gefähr acht Stunden wurde eine farblose Flüssigkeit erhalten, die von der unrerändert gebliebenen Cellulose abfiltrirt wurde. Beim Verdünnen mit Wasser schied sich ein feiner Krystallbrei ab, der sich nach näherer Untersuchung als Calciumsulfat erwies. In die nun schwachsauere Flüssigkeit wurde Schwefelwasserstoff eingeleitet, das ausgefällte Schwefelquecksilber abfiltrirt und der Schwefelwasserstoff auf dem Wasserbade verjagt. Das Zink lässt sich in Fällen, wie in dem vorliegenden, wo einerseits Zink und Eisen, andererseits Calcium und Phosphoräure nebeneinander auftreten, mit den sonst üblichen Reagentien nicht abscheiden. Die Phosphorsäure wurde deshalb nach dem bekannten Verfahren mit Zinn und Salpetersäure herausgeschaffit und dann das Zink aus der essigsauren Lösung mit Schwefelwasserstoff abgeschieden. Der weisslichgraue Niederschlag, der durch etwas Schwefeleisen verunreinigt war, wurde mit Essigsäure ausgewaschen, in Salzsäure gelöst, noch einmal als Zinksulfid ausgefällt und als Zinkoxyd zur Wägung gebracht. In $100 \mathrm{~g}$ der getrockneten. Pflanzen war 0,252 g Zinkoxyd (ZnO) entsprechend 0,2021 g Zink enthalten.

In einer zweiten Probe wurde das Zink elektrolytisch bestimmt. Gefunden wurden $0,2018 \%$ Zink.

Anmerkung. Noch mehr Litteratur über vorstehende Frage, als hier angegeben ist, und eine eingehendere Erklärung des verschiedenen Verhaltens des Zinkes in den Bodenarten findet sich in des Unterzeichneten Werke: "Die Verunreinigung der Gewässer etc.". Berlin 1899. 2. Aufl. II. Bd. 427-439.

J. König.

\title{
Ein einfacher Apparat zur gleichzeitigen Bestimmung des Fettes und des Wassers in der Butter.

\author{
Von
} \\ H. Poda, Adjunkt.
}

Mittheilung aus der statlichen Untersuchungsanstalt für Lebensmittel iu Graz. (Vorstand: Professor Dr. Prausnitz.)

Durch die vielfachen Verfälschungen der verbreitetsten Nahrungs- und Genussmittel ist das Bedürfniss nach einfachen, schnell arbeitenden Verfahren für eine möglichst genaue Untersuchung immer mehr zu Tage getreten.

Diesem Bedürfniss verdankt auch die im Folgenden zu beschreibende Methode zur schnellen Feststellung des Wasser- und Fettgehaltes der Butter ihr Entstehen. Sie unterscheidet sich von anderen rasch auszuführenden Methoden besonders dadurch, dass die zur Untersuchung verwandte Butter nicht abgewogen zu werden braucht.

Ausführung der Methode.

1. Ein Becherglas von etwa $20 \mathrm{~cm}$ Höhe und $15 \mathrm{~cm}$ Durchmesser oder 
besser noch ein Emailtopf oder Kupfergefäss wird bis $2 \mathrm{~cm}$ unterhalb des Randes mit Wasser gefüllt und das Wasser zum Sieden erhitzt.

2. In den gut gereinigten und trockenen Butt er pr ü fer (Fig. 20) lässt man mit der beigegebenen Pipette $8 \mathrm{ccm}$ Schwefelsäure (spec. Gew. $1,64=72 \mathrm{Ge}-$ wichtsprocente) derart einfliessen, dass man zuerst die gefüllte Pipette bis an den Boden des Butterprüfers einsenkt und erst wenn sie ausgelaufen ist, rasch herauszieht. Hierbei ist möglichst zu vermeiden, dass die Wandungen des Butterpriifers mit Schwefelsäure benetzt werden.

3. Der Apparat wird jetzt mit Hilfe der Vorrichtung, Fig. 21, 5 Minuten lang senkrecht in das siedende Wasserbad eingehängt (Fig. 22) und der Säure-

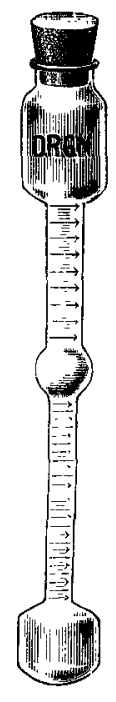

Fig. 20.

1;3 natürl. Grö́sse.

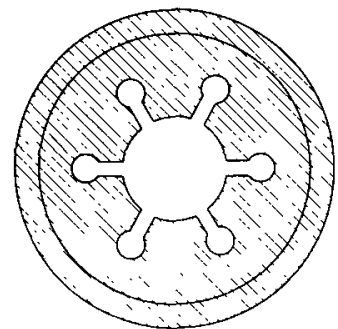

Fig. 21.

1/6 natürl. Grösse.

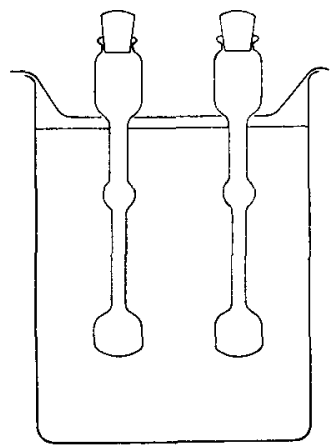

Fig. 22.

1/6 natürl. Grösse.

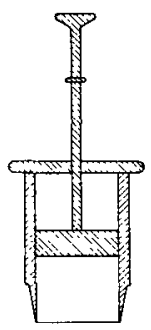

Fig. 23.

1/2 natürl. Grösse.

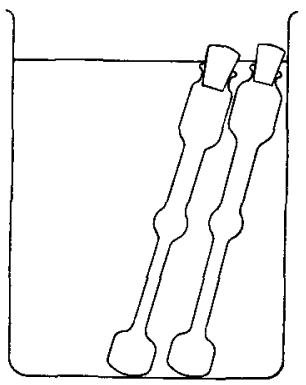

Fig. 24.

1/6 natürl. Grösse.

stand abgelesen. Um eine Zusammenziehung durch Abkühlung zu verhindern, ist es angezeigt, besonders bei den ersten Untersuchungen, die der Analytiker mit diesem Apparat macht, die Ablesung auszuführen, während sich der Apparat noch im siedenden Wasser befindet. Es wird deshalb der Butterprïfer an die vordere Wand des Wasserbades angelegt und der Säurestand gegen das Licht abgelesen und notirt. In dieser Weise ist eine bis auf $2 / 10$ genaue Ablesung leicht möglich.

4. Mit dem Butterstecher (Fig. 23) wird eine Probe aus der gut gemischten Butter in der Art entnommen, dass man den Butterstecher in die Butter eindrückt, bis sich derselbe vollkommen mit der Butter gefüllt hat. Steht nur 
eine geringe Menge Butter zur Verfügung, so wird der Butterstecher nach und nach mit der Butter gefüllt. Es wird sodann die äussere Seite des Butterstechers sorgfältig abgewischt, der Stecher in den Butterprüfer eingesetzt und durch Nachdrücken des Stempels die Butterprobe in den Prüfer eingeführt.

5. Nach Herausnahme des Butterstechers wird der Prïfer gut verschlossen und einige Male tüchtig durchgeschüttelt, bis die Mischung ein gleichförmig trübes Aussehen bekommen hat. Der Apparat wird nun 3 Minuten in das siedende Wasserbad derart eingelegt, dass das Wasser ihn bis zum Gummistöpsel umspült (Fig. 24).

6. Der Butterprüfer wird jetzt. 2 Minuten in der Gerber'schen Centrifuge centrifugirt. Findet hierbei ein scharfes Absetzen der verschiedenen Schichten nicht statt, so wird noch ein zweites, nöthigenfalls sogar ein drittes Mal nach vorausgegangenem Durchschütteln und Erwärmen im Wasserbade centrifugirt. Die Fettschicht soll klar sein und sich haarscharf von der dunklen Schwefelsäure abtrennen. Hierauf wird der Apparat noch 4 Minuten in das siedende Wasserbad eingehängt und der untere und obere Stand der Fettschicht abgelesen. Ein zu langes Erwärmen im Wasserbade ist zu vermeiden, weil die Fettschicht mit der Zeit (nach $1 / 2$ Stunde) dunkel wird, was für die Ablesung nachtheilig ist.

Berechnung der Ergebnisse.

Von dem oberen Stand der Fettschicht wird der untere Stand derselben abgezogen (f) und von dem unteren Stand der Fettschicht der zuerst vermerkte Stand der Schwefelsäure abgezogen (w).

Aus diesen beiden Werthen $f$ und w werden die Gewichtsprocente von Wasser + Nichtfett mit Hilfe der folgenden Formeln berechnet.

$$
\begin{aligned}
& \text { Wasser }+\operatorname{Nichtfett}(x)=\frac{100}{1+0,848 \frac{\mathrm{f}}{\mathrm{w}}} \% . \\
& \text { Gewichtsprocente Fett }(y)=100-\mathrm{x} .
\end{aligned}
$$

Beispiel:

$$
\begin{aligned}
& \text { Stand der Schwefelsäure vor der Bestimmung }=0,8 \\
& \text { Unterer Stand der Fettschicht } \quad=14,4 \\
& \text { Oberer Stand der Fettschicht }=87,8 \\
& \mathrm{f}=87,8-14,4=73,4 \\
& \mathrm{w}=14,4-0,8=13,6 \\
& \text { Gewichtsprocente Wasser }+\operatorname{Nichtfett}(x)=\frac{100}{1+0,848 \cdot \frac{73,4}{13,6}}=17,97 \% \text {. }
\end{aligned}
$$

$$
\text { Fett }(y)=100-17,97=82,03 \% \text {. }
$$

Mit diesem Apparat sind von mir in unserer Anstalt und von anderen Analytikern in anderen Anstalten Kontrolluntersuchungen ausgeführt worden, welche die in der nachfolgenden Tabelle aufgeführten Werthe ergaben. Sie zeigen, dass die Parallelbestimmungen gut unter einander übereinstimmen und 
dass die Bestimmungen gegenüber den gewichtsanalytischen Differenzen im Fettgehalte von selten über 0,4 in der Regel sogar nur $\pm 0,2 \%$ ergaben, so dass dieser Apparat für die Praxis völlig ausreichend genaue Ergebnisse liefert. Hierbei ist noch zu bedenken, dass Butterproben niemals so gleichmässige $\mathrm{Zu}$ sammensetzung (Wassergehalt) haben, wie andere Substanzen, weshalb die an und für sich kleinen Differenzen der gewichtsanalytischen Methode gegenüber noch weniger von Bedeutung sind.

\begin{tabular}{|c|c|c|c|c|c|c|c|c|c|c|}
\hline \multirow{2}{*}{$\begin{array}{c}\text { Butter } \\
\text { No. }\end{array}$} & \multicolumn{4}{|c|}{$\begin{array}{l}\text { Gewichtsanalytische } \\
\text { Bestimmungen }\end{array}$} & \multicolumn{3}{|c|}{ Nach Gerber } & \multicolumn{2}{|c|}{$\left|\begin{array}{c}\text { Nach dem neuen } \\
\text { Verfahren }\left(\mathbf{P}_{0} \text { d } \mathbf{a}\right)\end{array}\right|$} & \multirow{2}{*}{$\begin{array}{c}\text { Analy- } \\
\text { tiker }\end{array}$} \\
\hline & $\begin{array}{c}\text { Fett } \\
\% \\
\end{array}$ & $\begin{array}{c}\text { Wasser } \\
\% \\
\end{array}$ & $\begin{array}{c}\text { Nichtfett } \\
\%_{0} \\
\end{array}$ & $\begin{array}{c}\begin{array}{c}\text { Wasser } \\
\text { und } \\
\text { Nithtfett } \\
\text { o }\end{array} \\
\end{array}$ & $\begin{array}{c}\text { Fett } \\
0 \\
\end{array}$ & $\begin{array}{c}\text { Wasser } \\
0 \\
0\end{array}$ & $\begin{array}{c}\text { Wasser } \\
\text { und Nichit- } \\
\text { fett (Dif- } \\
\text { ferenz) } \\
v_{0}\end{array}$ & $\begin{array}{c}\text { Fett } \\
\% \\
\end{array}$ & $\begin{array}{c}\text { Wasser } \\
\text { und } \\
\text { Nichtfett } \\
\text { \% }\end{array}$ & \\
\hline 1 & $\begin{array}{l}83,77 \\
83,95\end{array}$ & $\begin{array}{l}14,92 \\
15,03 \\
14,98 \\
15,03\end{array}$ & 1,08 & 16,07 & $\begin{array}{l}84,46 \\
84,21\end{array}$ & $\begin{array}{l}15,50 \\
15,66\end{array}$ & $\begin{array}{l}15,54 \\
15,79\end{array}$ & $\begin{array}{l}84,10 \\
84,04 \\
84,07 \\
84,26\end{array}$ & $\begin{array}{l}15,90 \\
15,96 \\
15,93 \\
15,74\end{array}$ & \\
\hline 2 & $\begin{array}{l}83,94 \\
84,10\end{array}$ & $\begin{array}{l}13,75 \\
14,06\end{array}$ & 1,23 & 15,16 & $\begin{array}{l}84,90 \\
85,70\end{array}$ & $\begin{array}{l}15,63 \\
14,21\end{array}$ & $\begin{array}{l}15,10 \\
14,30\end{array}$ & $\begin{array}{l}84,96 \\
84,89\end{array}$ & $\begin{array}{l}15,04 \\
15,11\end{array}$ & Inst \\
\hline 3 & $\begin{array}{l}81,72 \\
81,36\end{array}$ & $\begin{array}{l}17,11 \\
16,88\end{array}$ & 1,17 & 18,16 & $\begin{array}{l}82,70 \\
82,54\end{array}$ & $\begin{array}{l}16,10 \\
16,70\end{array}$ & $\begin{array}{l}17,30 \\
17,46\end{array}$ & $\begin{array}{l}81,92 \\
81,96\end{array}$ & $\begin{array}{l}18,08 \\
18,04\end{array}$ & tut 1 \\
\hline 4 & $\begin{array}{l}69,32 \\
69,18\end{array}$ & $\begin{array}{l}28,12 \\
28,19\end{array}$ & 1,05 & 29,20 & $\begin{array}{l}71,06 \\
71,59\end{array}$ & $\begin{array}{l}26,45 \\
27,41\end{array}$ & $\begin{array}{l}18,94 \\
18,41\end{array}$ & $\begin{array}{l}70,81 \\
70,79\end{array}$ & $\begin{array}{l}29,19 \\
29,21\end{array}$ & \\
\hline 5 & 83,72 & $\begin{array}{l}15,09 \\
15,03\end{array}$ & 1,17 & 16,26 & $\begin{array}{l}83,96 \\
83,52\end{array}$ & $\begin{array}{l}14,66 \\
15,06\end{array}$ & $\begin{array}{l}16,04 \\
16,48\end{array}$ & $\begin{array}{l}83,59 \\
83,70\end{array}$ & $\begin{array}{l}16,41 \\
16,30\end{array}$ & \\
\hline 6 & $\begin{array}{l}83,44 \\
83,32\end{array}$ & - & - & $\begin{array}{l}16,55 \\
16,69\end{array}$ & $\begin{array}{l}83,76 \\
83,76\end{array}$ & - & $\begin{array}{l}16,24 \\
16,24\end{array}$ & $\begin{array}{l}83,45 \\
83,27\end{array}$ & $\begin{array}{l}16,55 \\
16,73\end{array}$ & \\
\hline 7 & 86,55 & 13,46 & - & 13,45 & 87,03 & - & 12,97 & 86,67 & 13,33 & tut 2 \\
\hline 8 & 98,34 & 1,66 & - & 1,66 & $\begin{array}{l}97,49 \\
98,82\end{array}$ & - & $\begin{array}{l}2,51 \\
1,18\end{array}$ & $\begin{array}{l}98,92 \\
98,92\end{array}$ & $\begin{array}{l}1,08 \\
1,08\end{array}$ & \\
\hline 9 & $\begin{array}{l}85,99 \\
86,12\end{array}$ & - & - & - & - & 一 & - & $\begin{array}{l}85,48 \\
85,49\end{array}$ & - & \\
\hline 10 & $\begin{array}{l}84,35 \\
84,55\end{array}$ & - & - & - & - & - & - & $\begin{array}{l}84,30 \\
84,10\end{array}$ & - & $\begin{array}{l}\text { Insti- } \\
\text { tut } 3\end{array}$ \\
\hline 11 & $\begin{array}{l}84,15 \\
84,28\end{array}$ & - & 一 & - & - & - & - & $\begin{array}{l}84,50 \\
84,70\end{array}$ & - & \\
\hline 12 & $\begin{array}{l}85,99 \\
86,12\end{array}$ & - & - & - & - & - & - & 85,46 & $\begin{array}{l}14,52 \\
14,56\end{array}$ & \\
\hline 13 & $\begin{array}{l}84,35 \\
84,55\end{array}$ & - & - & - & - & - & - & 84,20 & $\begin{array}{l}15,70 \\
15,90\end{array}$ & $\begin{array}{l}\text { Insti- } \\
\text { tut } 4\end{array}$ \\
\hline 14 & $\begin{array}{l}84,28 \\
84,15\end{array}$ & - & - & - & - & - & - & 84,60 & $\begin{array}{l}15,30 \\
15,50\end{array}$ & \\
\hline 15 & 92,41 & 7,19 & 0,40 & 7,59 & - & - & - & 92,63 & 7,37 & \\
\hline
\end{tabular}


Ausser der Genauigkeit der Ergebnisse bietet die neue Methode noch folgende Vortheile:

1. Sie erfordert keine Waage und kein Thermometer, da die Abwägung einer bestimmten Buttermenge und das Einstellen einer bestimmten Temperatur nicht nothwendig ist. Die Methode ist deshalb auch für solche Personen geeignet (Molkereibetriebe), welchen das Arbeiten mit einer analytischen Waage und mit einem Thermometer nicht gut überlassen werden kann.

2. Die Bestimmungen erfordern nur wenig Zeit. Wenn eine genügende Anzahl von Apparaten vorhanden ist, können in einer halben Stunde sechs Bestimmungen ausgeführt werden.

Ich glaube daher, dass sich die neue Methode leicht einbürgern, und besonders den Molkereibetrieben, der Marktkontrolle und den Untersuchungsanstalten gute Dienste leisten wird.

Die Butterprüfer, für welche Gebrauchsmusterschutz eingereicht wurde, und sämmtliche dazu gehörigen Apparate werden von der Firma Franz Hugershoff in Leipzig hergestellt.

\section{Berichtigung.}

Im zweiten Hefte der, ,Vereinbarungen zur einheitlichen Intersuchung und Beurtheilung von Nahrungs- und Genussmitteln, sowie Gebrauchsgegenstïnden für das Deutsche Reich"6 hat auf Seite 83 durch ein Versehen beim Druck entgegen dem Beschlusse der Kommission von Nahrungsmittelchemikern vom 5. und 6. August 1897 der Satz Zeile 15 bis 13 von unten:

„8. Fruchtessige, überhaupt Essigsorten, deren Abstammung im Handelsverkehr genau angegeben wird, dürfen keine Beimengungen von Spiritusessig oder dem aus Essigsäure oder Essigessenz hergestellten Erzeugniss enthalten." Aufnahme gefunden.

Die Kommission hat in der Sitzung vom 5. Januar d. J. beschlossen, an dem früheren Beschlusse festzuhalten, und in Ausführung desselben diesen Satz wieder zu streichen.

Berlin, den 31. März 1901.

Der Vorsitzende der Kommission. gez. Dr. Köhler, 